Motrivivência $\quad$ Ano XX, No 30, P. 169-184 Jun./2008

\title{
A Dialética da Teoria Racialista como saber para Problematizar em Pesquisas sobre Questões Raciais no Campo da Educação Física Escolar
}

\section{The Dialectic Of Racilism Theory How To Know For To Problemize In Research About Racial Questions At Physycal Education Classrom Field}

Marcelo Siqueira de Jesus

\begin{abstract}
Resumo
O presente texto faz uma apresentação sobre a moderna teoria científica racialista na sociedade francesa entre o final do século XVII até o século XIX. O intuito é relativizar este conhecimento com professores e educadores que atuam no ensino e na pesquisa cujo campo de investigação seja a educação física escolar (Escola Básica) e que adotem como referencial metodológico e

filosófico a "cultura corporal". A questão racial é privilegiada neste artigo e atende as indicações sobre a

Lei $\mathrm{n}^{\circ}$ 10.639/03.

Palavras-chave: Eurocentrismo, racialismo e cultura corporal

Abstract

This present paper made discussion about a scientific modern racialism theory in France society between finish sec. XVII and sec XIX. The intuit is to dialog this knowledge with teachers and researchers that working, teaching and researching whose investigation field is on physical education classroom (elementary and high schools) and use how methodology and philosophy reference a "corporal culture". The racial question is major this article and represent informs about brazilian Law $n^{\circ}$ 10.639/03. Keys-word: Eurocentrism, racialism, corporal culture

1 Mestre Pela Universidade Federal Fluminense, em 2009. Professor da escola básica nas redes estadual de ensino-RJ e municipal de São Gonçalo-RJ. Pesquisador do Penesb-UFF. Contato: marcelosjesus1975@hotmail.com
\end{abstract}


Situações contemporâneas de racismo no esporte e na sociedade

Nessa década retomam algumas situações de racismo e as suas conseqüências em diferentes setores da sociedade, principalmente quando se trata de questões de raça, religião e de gênero como forma de hierarquizar e de submeter aqueles que não possuem o tipo ideal ${ }^{2}$ estipulado pelo universalismo do eurocentrismo e, promove situações de inferioridade e subalternização aos que são considerados diferentes.

Como forma de informação e reflexão, aproveito nesse início para citar os recentes acontecimentos sobre a forma de olhar o outro como subalterno e inferior. Pensamos que esse comportamento fere o trato sobre a diversidade humana e também os direitos humanos. Essa problemática torna-se elemento de interesse investigativo em áreas como esporte, antropologia, ciências biológicas, ciências sociais, cultura e na religião.

Sobre o esporte, citamos três situações vivenciadas por desportistas e que foram amplamente divulgados pela mídia, por se caracterizarem como ações que podem ser consideradas semelhantes aos modelos adotados pelos racialistas de promover a inferioridade ao outro. Como primeiro caso: o jogador de futebol Roberto Carlos atualmente jogando na Turquia, durante a sua passagem pelo clube espanhol Real Madrid sofreu durante algumas partidas insultos dos torcedores adversários, emitiam das arquibancadas, sonoridade semelhante ao que primatas ecoam em seu habitat natural. Em outro momento, este mesmo atleta sofreu agressão fora do ambiente de jogo com palavras que o menosprezava e alcançando ações materiais como a inscrição em seu veículo com a palavra "monkey".

$\mathrm{Na}$ América Latina também tivemos casos que caracterizam o racismo, durante a disputa do campeonato de Futebol " $\mathrm{Li}$ bertadores da América" jogavam na cidade de São Paulo no ano de 2005 os clubes São Paulo F.C versus Racing Club da Argentina. Quando numa disputa de ataque o jogador do clube brasileiro que atende pelo apelido "Grafite" foi agredido pelo jogador Desábato, defensor da equipe Argentina, com palavras que o discriminava. Dessa maneira, o esporte também apresenta a faceta

2 Não estamos fazendo menção ao "tipo ideal" weberiano, apenas ao modelo originado nas estratificações e hierarquizações raciais surgidas a partir da teoria racialista que apresentaremos no decorrer deste ensaio. 
dessa cultura racialista espalhada pela forma universal de rotular e agir com atos opressores para subjugar e discriminar alguém.

A terceira ação racista que apresento no campo do fenômeno futebol foi o comentário do expresidente da Rússia quando no ano de 2007 declarou que os clubes de seu país estavam parecidos com os da África pelo fato de terem muitos negros em seu grupo de jogadores, isso não o agradava. Pensamos que para um chefe de Estado declarar esse tipo de pensamento que desvalorize a condição de diversidade humana presente num esporte como o futebol é uma atitude racista.

Em atividades estudantis, também apresentam atos de preconceito, em Junho de 2008, alguns estudantes brasileiros, latinos e africanos tiveram sua entrada no aeroporto de Madrid (Espanha) negada mesmo com a comprovação e autorização para permanência no país. Tiveram de ser deportados como forma repreensiva do governo espanhol na justificativa de proteção as suas fronteiras, algo que não se torna particular somente nesse país e sim freqüente na Europa.

Outro caso que merece destaque aconteceu durante prática de Lazer na Itália, descrita no dia 02/08/08 no portal G1 das organizações Globo. Duas meninas, irmãs, entre 10 e 13 anos de idade, nadavam numa praia próxima de Nápoles (Itália). Muitos banhistas estavam presentes quando as duas se afogaram, seus corpos foram resgatados da água e permaneceram durante longo período cobertas pelas próprias roupas (saia e blusa). As pessoas que estavam ao redor dos corpos foram questionadas se não as importunavam a presença próxima delas de duas crianças mortas, a resposta dos banhistas foi: "elas eram apenas ciganas". Na Itália, cresce a presença da população de ciganos oriundos de países como a Hungria, através do processo de migrações no continente europeu.

Na cidade do Rio de janeiro, no ano de 2008, um centro de manifestação religiosa brasileira de matriz africana foi invadido por manifestantes ligados a uma instituição religiosa protestante $\mathrm{e}$ fizeram uma verdadeira inquisição no século XXI, quebrando imagens, símbolos religiosos e danificando todo o ambiente. Algumas ações contra umbandistas e pessoas ligadas ao candomblé são freqüentes nas cidades brasileiras.

Seja por esses fatos ou mesmo através do interesse que mobilize a diferenciar o outro como forma de ferir os direitos humanos é que surge o interesse de dialogar sobre o tema racismo em aulas de Educação Física na Educação Básica ou mesmo no Ensino Superior como meio de 
atender a cultura corporal como concepção sócio-histórica. Assim, penso em questões que podem ser compartilhada com educadores e pesquisadores para buscarmos relativizar sobre a problemática racial no Brasil: Por que ainda presenciamos situações de racismo na sociedade? Por que apesar de todas as atrocidades que as teorias racialistas já promoveram para a humanidade, ainda são presentes e ressignificadas? Qual o papel do profissional de Educação Física sobre esse fato? Esta sendo oferecido o conhecimento sobre cultura africana e afro-brasileira nas escolas básicas brasileiras? O currículo de Educação Física escolar atende as diretrizes da Lei 10.639/03?

Não pretendo responder essas questões nesse ensaio e nem mesmo tenho essa pretensão, apenas estou iniciando na prática como pesquisador o diálogo e a tentativa de trazer para a área uma contribuição que possa facilitar o debate sobre esse tema com importante relevância para a formação humana. Acredito que os profissionais de Educação Física possam oferecer aos nossos educandos uma idéia daquilo que não pode configurar na subjetividade humana que é o racismo e as suas conseqüências. Para isso apresento a origem da teoria do racismo na sociedade francesa entre os séculos XVII e XIX como meio de divulgar e oportunizar colegas a conhecerem a história de como foi pensada a diversidade humana através das ciências naturais e que sentimos as suas consequencias até os dias de hoje.

\section{O surgimento do racialismo}

Em relação à Dialética, Minayo (2004) apresenta-se como método de abordagem do real, no entender o processo histórico e seu dinamismo, apreender a prática social empírica dos indivíduos em sociedade (nos grupos e nas classes sociais) e realizar críticas às ideologias (p. 65).

Pensamos nessa corrente para dar significância e arcabouço metodológico para a nossa apresentação textual. Selecionamos para esse dialogo a obra "Nós e os Outros" de Todorov (1993), em sua análise sobre a sociedade francesa entre os séculos XVII e XIX, o autor trata a questão da diversidade humana. De início, considera que, à discussão sobre o universal e o particular são importantes para se afirmar que o "problema de unidade e da diversidade se transforma no problema do universal e do relativo" (p. 21).

Referindo-se à opção universalista, Todorov afirma que o etnocentrismo é o principal movimento que influencia os valores universais, associados aos da própria sociedade a que o indivíduo pertence. 
Considera também que o etnocentrismo contribuiu para promover uma visão pseudocientífica, utilizada pelos colonizadores europeus ao considerarem a pretensão universal e o seu conteúdo particular para justificar suas ações sobre os povos colonizados. Hyppolite Taine (apud Todorov, 1993) foi um dos principais criadores desse pensamento francês, em sua obra Les origines de la France Contemporaine (1876-1896) dos séculos XVIIXVIII, buscando, assim, como toda corrente de pensamento da época, imaginar o homem de maneira geral (Ibidem, p. 22). Outra importante contribuição para a legitimidade desse equivocado movimento foi a obra de Pascal, quando escreveu Primeira parte: miséria do homem sem Deus; Segunda parte: Felicidade do homem com Deus (16571662, apud Todorov, 1993, p. 22), em que relata a figura humana no singular. A partir daí, desenvolveuse a concepção universalista que reconhece a diversidade humana através da identificação de toda a sociedade a um único grupo social.

O etnocentrismo apresenta uma caricatura natural universalista, segue a linha do menor esforço e procede de maneira não crítica ao crer que seus valores são verdadeiros e isso lhe basta, não os precisando provar.

O nascimento do etnocentrismo se dá através dos costumes, dos valores e da religião, a partir do raciocínio que Pascal apresenta sobre as características de um universalismo não crítico. Dessa forma, surgem ideias que incorporam a lógica do conceito, destacando-se La Bruyère (apud Todorov, 1993), seguidor de Montaigne, ao apresentar um universalismo com uma tolerância limitada, com forte influência numa centralização (Ibidem, p. 23-24). A proximidade entre conhecer o outro e a ciência natural formula os conceitos do etnocentrismo científico de Joseph Marie de Gerando (Ibidem), que parte de um quadro universalista e racionalista na sua definição geral, pretendendo também saber como se situam em suas particularidades, quando está em destaque o tipo ideal humano, através do padrão de características do fenótipo.

\section{Hierarquizações a partir de aspectos do fenótipo}

A forma com que essa ciência etnológica surge deixa um rastro de críticas e afirmações; dentre elas, destaca-se a que considera a diversidade humana como algo que deve fugir de padrões e hierarquizações. Esses questionamentos têm, como ponto de partida, o que foi relatado como julgamento de valor entre as formas descritas sobre o outro, quando os navegantes viajaram para a África e para o Continente Americano. De imediato, a visão que 
deles se destacou estava carregada do sentimento da superioridade de um homem em relação ao outro; analisaram o modo de vida dos povos e consideraram suas posições como inferiores, em confronto com os hábitos do homem europeu dito "civilizado". Rousseau ${ }^{3}$ (apud Todorov, 1993) foi um dos principais idealizadores dessas críticas, apesar de se considerar que este autor não negou o seu universalismo, quando julgou ser necessário melhor conhecer esses povos através de suas conformidades e diferenças, passando, dessa maneira, a adquirir informações universais sobre eles.

A partir dessas análises do próprio grupo humano, que apresenta aspectos biológicos diferentes, surgem o racismo e o racialismo, que foram considerados legítimos e geraram desigualdades a partir de equívocos que permeiam as relações sociais. Para Todorov (1993), racismo é uma prática excludente, enquanto o racialismo se apresenta como teoria produzida a partir de diferenças constatadas. Tais diferenças apresentam-se no campo biológico, cultural, linguístico e nos limites entre identidade e diferença.

O racismo, como prática excludente, pode gerar uma catástrofe (por exemplo: o holocausto), utilizando-se para isso do racialismo e de suas doutrinas, que classificam a humanidade a partir de suas características fenotípicas e pela frenologia.

A análise feita pelo pensamento francês sobre a diversidade humana provocou o aparecimento do racismo científico, que afirmou a existência de uma hierarquia humana com base biológica, hierarquia esta que tem uma suposta analogia com a produção cultural dos diferentes grupos.

O racialismo iniciou-se na Europa Ocidental, entre os séculos XVIII e XX, como movimento de ideias voltadas para designar o "tipo ideal", sentido este que não referimos ao modelo weberiano, apenas ao conceito legitimado pela estratificação racial. O uso e os sentidos desses conceitos foram afirmados por intelectuais como François Bernier, que, em 1684, "utiliza a palavra racismo pela primeira vez

3 Propôs ainda que era preciso distinguir dois aspectos nesse estudo: o primeiro, descobrir a especificidade de cada povo e suas eventuais diferenças em relação a nós. Para isto, é preciso ser instruído, desinteressado e saber livrar-se dos preconceitos nacionais do etnocentrismo. $\mathrm{O}$ segundo, sendo necessário, uma vez reveladas essas diferenças, voltar à ideia universal do homem num sentido que não seria o resultado da pura especulação metafísica, mas que absorveria o conjunto dos conhecimentos empíricos. Considera também que o bom universalismo não deduz a identidade humana de um princípio, qualquer que seja ele, que parte de um conhecimento aprofundado do particular. (Todorov, 1993, p. 30). 
em seu sentido moderno" (Todorov, 1993, p. 113). Seu interesse em conceituar essa ideia partiu de algumas situações em disputa na França sobre diferenças raciais entre francos e gauleses, que caracterizavam ancestrais dos aristocratas e do povo.

A investigação sobre a definição e a busca de um tipo ideal humano com características do fenótipo levou esses intelectuais do racismo científico a elegerem o homem como seu principal objeto. Buffon, na criação de Histoire naturelle, volume "De I'homme" (1749), corrobora este sentido, quando realiza a síntese de numerosos relatos de viagem entre os séculos XVII e XVIII. Esse ensaio exerceu uma influência decisiva sobre a literatura posterior, que busca construir uma unidade do gênero humano (apud Todorov, 1993, p. 113-114).

Não por razões teológicas, ele defende a monogênese e assume a posição de naturalista, que se apoia nos fatos, considerando que brancos e negros podem procurar a união em favor de uma única espécie; ainda sobre a unidade do gênero humano, tem como corolário a diferença radical entre o homem e os animais. A humanidade tem a razão, reconhecendo sua presença a partir do uso de signos intencionais. Quando o homem mostra um signo exterior, mostra o que de fato está sentindo e, dessa maneira, a palavra torna-se o signo comum.
Como resultado de sua investigação, Buffon (1749) propõe uma hierarquização na relação entre os animais na natureza. Considera que os homens pertencem a uma única espécie e pode-se julgá-los, utilizando os mesmos critérios. No entanto, esta posição afirma o caráter determinista sobre a diferença $\mathrm{e}$ a superioridade entre uns e outros. Hierarquia e unidade se mensuram por julgamentos de valor: a primeira, pela observação de outra característica humana; já a segunda é provada pela fecundação mútua.

Outro grau de reconhecimento dessa hierarquia, proposta por Buffon (apud Todorov, 1993), é através da sociabilidade, e sobre esse conceito o autor associa que o homem somente se pode manter no topo da vida biológica pelo fato de comandar a si mesmo, domar-se, submeter-se a leis. Para concluir sobre o grau de civilidade que um povo pode alcançar, relata ser necessário que haja a existência de leis, de ordem estabelecida, de usos constantes e costumes fixos.

Esse método investigativo utiliza técnicas e instrumentos intelectuais da língua e da escrita para chegar à racionalidade. Portanto, racionalidade e sociabilidade estão presentes em todos os homens. Esse sentido permitiu a Buffon gerar oposições como: a civilização ou a polidez versus barbárie e a selvageria. 
A exposição sobre as variedades na espécie humana se articula com essa hierarquização. Pensa que, no alto, estão as nações da Europa setentrional, abaixo, os outros europeus, em seguida, as populações da Ásia e da África e, por fim, estão os selvagens americanos. A presença de qualquer diferença social (de costumes e de técnicas), bem como em qualquer uso da razão, levou-o a formular julgamentos de valor sobre os povos, colocando em questão a unidade do gênero humano.

Quando se interroga sobre o que constitui a variedade na espécie humana, o referido autor enumera três parâmetros: a cor da pele, a forma e o tamanho do corpo e o natural/costume ${ }^{4}$. A cor da pele depende do clima e de outras causas que se relacionam com a maneira de viver, o nível de civilização e a alimentação. Os civilizados escapam da miséria, os selvagens sofrem a fome e as intempéries, levando-os a viverem como animais.

Dessa forma, físico e moral são ligados na teoria racialista através desses escritos de Buffon (apud Todorov, 1993), quando considera a existência das raças como uma evidência e afirma a solidariedade do físico e da moral, subentendida segundo a determinação do indivíduo pelo grupo, levando-o a proclamar um sistema único de valores.

Outro ponto em destaque no pensamento deste autor é a estética, em conjunto com a ética, quando descreve que a população africana possui as mesmas ideias que os europeus sobre a beleza, no desejo de terem belos olhos, uma boca perfeita, lábios proporcionados e nariz bem-feito. Entretanto, o ideal estético proposto por Buffon (Ibidem) é estritamente etnocêntrico em relação ao ético e ao cultural. O homem europeu é o referencial e qualquer mudança de cor é considerada uma degenerescência. Seu discurso chegou a ser parâmetro prestigiado pela ciência.

O intelectual francês, Renan, na obra Histoire générale et systéme comparé des langues sémitiques (1855), descreve o seu racialismo a partir da oposição entre arianos e semitas e apresenta a definição de uma hierarquização dos indivíduos na categoria raça, através da divisão da humanidade em grupos raciais: branco, amarelo e preto.

Nessa estratificação racial, elege uma raça inferior como sendo a constituída pelos negros da África,

4 Os costumes agem por intermédio do clima e da alimentação, aumentando e diminuindo seus efeitos, e a falta de civilização produz a negritude da pele. Também sobre a comparação entre civilizado e bárbaro, se vivessem no mesmo clima, os selvagens seriam mais escuros, feios, menores e enrugados (Todorov, 1993, p.118). 
pelos nativos da Austrália e pelos índios americanos. Renan considera que existem representantes dessas raças por toda a terra, os quais são progressivamente eliminados por outras raças, afirmando que estas raças inferiores são incivilizáveis e não suscetíveis ao progresso. A raça intermediária é a amarela, representada pelos chineses, japoneses, tártaros e mongóis; suas características são de pouco civilizadas. Complementa a sua análise ao apontar que a língua chinesa apresenta estrutura inorgânica, incompleta e defeituosa. Na parte superior dessa escala, considera a branca submetida aos julgamentos absolutos de beleza e, também, por jamais ter conhecido o estado selvagem.

As suas ideias ajudaram a promover as desigualdades das raças humanas; afirma que os homens não são iguais e, com isso, as raças também não o são. Exemplifica isso ao tratar do negro, quando afirma que ele é feito para servir às grandes coisas desejadas pelos brancos e, se acontecesse de a terra se tornar coberta por eles, também aconteceria uma limitação total, gerando uma "mediocridade geral" (Todorov, 1993, p.125).

As consequências dessas práticas classificatórias são, na verdade, uma construção etnocêntrica para a sociedade. Em L'Avenir de la science, de 1848, Renan apresenta um projeto de educação que ainda guarda traços do espírito iluminista ${ }^{5}$. Porém, em L'Origine du langage, de 1848-1858, apresenta um projeto imperialista, considerando a raça ariana e a raça semítica destinadas a conquistar e a conduzir a espécie humana à unidade. A raça humana possui o papel de condução pela dignidade de sujeito humano, apresentada por ela; as outras raças se limitam a funções instrumentais e suas existências se dão, apenas, na ótica do projeto imperial ${ }^{6}$ predestinado para a raça branca. Considerando que todas as explicações da sociedade e das raças se encontram na natureza, então, as guerras de expansão se legitimam por permitirem a conquista dos povos diferentes dos europeus.

Outro aspecto destacado por Renan (apud Todorov, 1993) é sobre a forma pela qual a cultura e

5 Renan pensou num estado mundial (conduzir a espécie humana à unidade), as raças substituindo as classes. No entanto, ao revelar que tudo é obra da natureza, não há ideal comum à humanidade (Todorov, 1993, p. 125).

6 Exemplifica essa visão em La reforme intelectuelle et morale de la France, de 1871, quando retrata que a natureza produziu uma raça de operário, que é a chinesa; uma outra de trabalhador da terra, que é o negro; e uma raça de senhores e soldados, que é a raça europeia (apud Todorov, 1993, p. 126). 
a ciência são tratadas em $L$ 'Avenie de la sciense, de 1848, através dos exemplos e dos argumentos contidos para enaltecer a doutrina que professa. A ciência é o traço mais elevado da humanidade, seu maior título de glória; sem a ciência, a humanidade não mereceria respeito.

$U \mathrm{~m}$ aspecto importante destacado pelo autor é que ciência e a ética devem permanecer autônomas, e é essencial que as crenças morais e religiosas sintam o abrigo dos resultados com que a ciência pode conduzir suas deduções.

Como consequência dessa reflexão e relacionada à questão racial, Renan contestou a ausência de unidade e a impossibilidade da igualdade, tanto entre as três grandes raças (branca, amarela e negra) como no interior da raça branca. Ao separar ciência e ética, prioriza que os dogmas morais não devam impedir o trabalho da ciência, pois ela pode conduzir os homens ou justificar seu comportamento, ocupando o lugar da ética.

Considera que a razão se encarna melhor na ciência, por acreditar que ela é a alma da sociedade e associadas entre si criam uma superioridade militar e industrial. Criará, assim, a superioridade social, um estado da sociedade onde será obtida a quantidade de justiça compatível com a essência do universo, já que a ciência pro- move as respostas dos fenômenos a serviço da razão.

Já no final do século XIX, Renan passa a considerar outra análise importante sobre a existência da raça cultural; compreende que a língua desempenha um papel dominante na formação de uma cultura, quando ela transforma, quase completamente, a raça, na divisão dos grupos da humanidade pela língua, pela religião, pelas leis e pelos costumes.

Considera que as raças semítica e ariana são linguísticas, analisadas pelo estudo dos costumes, das literaturas e das religiões; só há um único critério para reconhecer os semitas, que é através da linguagem. A raça linguística não é uma raça física e nem uma nação, porque muitas línguas podem ser faladas no interior de uma mesma nação, como acontece na Suíça, ou, até, muitas nações podem falar uma única língua, como se faz no uso do inglês. Esse conceito está muito mais próximo da nação do que da antiga raça; assim, é a língua que faz o espírito da nação; com efeito, na diversidade das raças é preciso procurar as causas mais eficazes da diversidade dos idiomas.

Semelhantes às de Renan, ao propor uma classificação das raças, foram as ideias de Le Bon (apud Todorov, 1993), que ajudaram a difundir a ideologia da raça, numa 
adaptação da visão do intelectual anteriormente citado. Considera quatro graus de destaque na escala racial: na parte inferior, encontramse as raças primitivas, exemplificadas pelos indígenas australianos; afirma que esse povo estava fadado à não civilização e, no seu encontro com um povo superior, o seu destino seria o desaparecimento, como sendo um processo natural, sem definir a forma pela qual esse processo aconteceria.

Em seguida, encontram-se as raças inferiores e, como figura central, estão os negros; como Renan, considera que eles não se aperfeiçoaram, apresentando capacidades rudimentares de civilização, são também julgados bárbaros por sua capacidade cerebral ser inferior à dos brancos, condenados a permanecerem para sempre na barbárie. Afirma não encontrar, em toda a história das civilizações, exemplos de povoamento negro que alcançassem um determinado nível de civilização. Em terceiro plano, aparecem as raças médias, representadas pelos grupos étnicos chineses, japoneses, mongóis e povos semíticos. Tanto japoneses quanto árabes são agrupados em critérios de civilização. A sua conclusão foi tirada através da proposta da raça branca de Renan, com a divisão em arianos e semitas, além da evidente inferioridade destes últimos, levando-o a juntá-los aos representantes da raça amarela.

A descrição da escala hierárquica de Renan mostra que, no cume, está um único grupo humano, os povos indo-europeus, e o critério para essa afirmação e classificação se baseia na razão e nas consequências geradas pelas invenções técnicas e artísticas, na ciência e na indústria. Seu pensamento define as raças primitivas e inferiores como aquelas com uma capacidade inferior de raciocinar. Esses critérios tornaram-se parâmetro de análise e comparação para medir a capacidade de civilização de cada grupo racial.

Outra posição de Le Bon (apud Todorov, 1993) caracteriza-se por assimilar a hierarquia das raças à dos sexos e à das classes; entretanto, sua tese incorpora a questão racial, utilizando como referência o negro, mantendo-o sempre em posição inferior nas suas análises, e comenta, para justificar sua observação, que não é necessário ir até a África para observar as raças inferiores. Somente se faz necessário analisar os operários no interior de cada país em que se encontram incivilizados. Propõe também analisar a casa das pessoas; o lugar ideal pensado é a cozinha, para observar a mentalidade das raças primitivas em relação às esposas, comparativamente, quando esclarece que há um grande 
distanciamento entre as mentalidades. Sobre a prova da inferioridade feminina e a da proximidade das mulheres com os negros, elas são atribuídas aos estudos de craniologia, que são uma especialidade do autor; constata que os crânios dos homens brancos são maiores do que os dos negros, além de os dos machos brancos serem maiores do que os das fêmeas brancas.

Hypolite Taine (apud Todorov, 1993) tornou-se o mais importante intelectual, na segunda metade do século XIX, quando o assunto era o determinismo integral. Considerava que nenhum acontecimento ocorre sem causa: nossas maneiras de pensar, sentir e nossos atos são ditados por causas identificáveis; esse processo é integral, no sentido de tocar os menores elementos de cada fenômeno. $\mathrm{O}$ feito total é um composto, determinado por inteiro pela grandeza e pela direção das forças que o produzem. A procura das causas deve vir após a reunião dos fatos: sejam eles físicos ou morais, têm sempre causas, comparáveis à ambição, à coragem, à veracidade e ao movimento muscular para o calor animal.
Para descrever o mundo dos homens, Taine utiliza metáforas tiradas do Reino Vegetal: "as obras de arte são sementes que caem sobre um certo solo, que o vento varre que as neves congelam em seguida brotam e florescem" (Todorov, 1993, p. 130). A ciência tem o papel de ser o guia social para a humanidade. Nas diferenças entre ciência natural e humana está o funcionamento de suas respectivas matérias.

Taine professa um materialismo tão integral quanto determinista, dividindo os fatos naturalmente em indivíduos, espécie e gênero. $\mathrm{O}$ objeto se transforma constantemente; a molécula se transmite por hereditariedade e só se modifica lentamente sob a ação do meio. Aceita, do lluminismo, a fé no determinismo, tudo que ele segue; o que recusa é o universalismo, a fé na unidade essencial da espécie humana e na igualdade enquanto ideal; assim, ele se apresenta como discípulo fiel do materialismo e do cientificismo dos enciclopedistas, de Helvétius, Sade e Diderot.

As contribuições de Gobineau $^{7}$ (apud Todorov, 1993) para

7 Concorda com Taine que não há diferença entre o mundo da natureza e o mundo humano, descreve nas suas obras metáforas orgânicas: "as civilizações são masculinas e femininas, têm nascimento, vida, morte, têm germes, raízes podem ser podadas" (p. 137). Não há diferenças qualitativas entre ciências da natureza e ciências do homem, trata-se de fazer a história entrar na família das ciências naturais. Sobre as qualidades morais do indivíduo, diz que são inteiramente determinadas por suas disposições físicas; nesse sentido, mantêm-se oposto aos enciclopedistas, que acreditavam nas virtudes da educação e nos progressos possíveis, tanto do indivíduo quanto da espécie (apud Todorov, 1993, p. 137). 
as teorias racialistas se prendem ao determinismo, ao materialismo e à fé na ciência; para ele, o comportamento dos homens é dependente da raça a que pertencem e se transmite pelo sangue. Acredita, também, que as sociedades impõem às populações seus modos de existência, quando ditam elementos de suas leis inspiradas nas suas vontades. $\mathrm{O}$ indivíduo sofre a ação de forças que o transcendem; resta-lhe observar o curso da história, compreendê-la e com ela se resignar.

Sobre a teoria das raças, ele se torna um racialista fiel à grande corrente de pensamento da época. Vê diferença entre homens e animais, que consiste na presença ou na ausência da razão. Adere ao poligenismo de Voltaire, embora pretenda respeitar o dogma cristão da monogênese: "está consciente da eterna separação das raças" (apud Todorov, 1993, p. 143). Estas não são, apenas, diferentes, são hierarquizadas, seguindo escala única.

As representações da diversidade humana, na hierarquização proposta por Gobineau, sobre as três raças (negra ou melaniana, amarela ou finlandesa e branca), são identificadas por marcas físicas como a carnação, o sistema piloso, a forma do crânio e da face. Foram avaliados como resultado dos critérios de beleza, força física e capacidades intelectuais.
O belo, para ele, é uma ideia absoluta e necessária, que não poderia ter uma aplicação facultativa. A raça branca é considerada como ideal, a partir da relação estabelecida entre beleza e tipo europeu, considerado como referência para os não brancos. Sobre força física, a raça amarela é destacada como sendo fraca, e a dos negros tem menos rigor muscular, em comparação com a dos brancos, que ficam no topo da hierarquia racial, estabelecida pelo racialismo. Em relação às capacidades intelectuais, os negros são considerados medíocres ou nulos, e os amarelos, segundo o autor em questão, tendem à mediocridade; isso prova a imensa superioridade dos brancos em todo o campo da inteligência.

O autor em discussão toma o emprego do termo "civilização" em um sentido particular, a partir dos três graus atribuídos à humanidade em sua evolução: a tribo, a povoação e a nação. A raça é o resultado da verdadeira fusão de tribos anteriormente isoladas, quando seus solos são reunidos e suas populações se misturam. $\mathrm{O}$ traço que permite distinguir essas fases de evolução humana é sua relação com os outros. A presença da ignorância é considerada o grau mais baixo, enquanto a interação se torna referencial para o grau mais elevado nessa análise. 
Outra hierarquia proposta por Gobineau (apud Todorov, 1993), refere-se ao estatuto e ao papel do ideal na vida de uma sociedade. Assim, no grau mais baixo encontra-se aquele que não consegue separar-se do real e, quando consegue, não age sobre ele. Nesse sentido, a população está condenada à imobilidade. Num grau médio, a população tem um ideal que lhe permite modificar seu estudo presente. No terceiro grau, esse ideal age não apenas sobre a população onde surge, mas também sobre os outros povos. Eleva-se em imensas regiões o domínio incontestado de um conjunto de ideias e de fatos, mais ou menos bem coordenados, que podem ser chamados de civilização.

Na ótica da raça, a mistura é uma degradação e toda degradação é o efeito de uma mistura de sangues. Os povos só degeneram em seguida às misturas e na proporção em que sofrem. Sobre a categoria degenerado, ela é aplicada a um povo quando significa que ele não tem mais o valor intrínseco que outrora possuía, porque não tem mais, nas veias, o mesmo sangue, cujo valor foi gradualmente modificado pelos sucessivos acréscimos.

Nesse sentido, raça e civilização são entidades ligadas entre si, o mais estreitamente possível, e, talvez sejam apenas dois aspectos de uma única entidade, que é a socieda- de. Mas, vista como civilização, ela é tanto mais forte quanto mais assimila diferentes sociedades; enquanto, na ótica da raça, quanto mais é misturada, mais fraca se torna.

\section{Considerações finais}

A questão do racismo está principalmente inserida no campo de discussões sobre identidade e da diversidade humana, presentes nas teorias pedagógicas do multiculturalismo crítico defendida por Peter Mclaren e pela corrente progressista de Snyders (Silva, 2005). Essas concepções adotam como principal foco o combate as relações de poder e, sua intervenção pedagógica se dá através da tolerância ao outro, exemplificado em ações e conteúdos curriculares que considerem o conhecimento empírico do aluno e as outras formas de transmissão do saber. Entretanto, quem tolera alguém pode gerar uma hierarquização, dessa forma o diálogo proposto pela interculturalidade pode ser o modelo considerado nesse contexto, por ele se associar ao processo de conscientização sugerida por Paulo Freire, no uso de ações dialógicas como meio de superar a alienação do sujeito em relação a sua condição no mundo.

Sobre o racismo, a sua presença no esporte e no lazer justifica o diálogo na área da Educação 
Física inserindo ideias e categorias das diferentes correntes epistemológicas contribuindo para a formação dos indivíduos através do campo da cultura, da sociologia e da história. Este ensaio faz menção de ser necessário dar oportunidade de conhecer outra história no currículo escolar, conforme Meneses (2008) menciona sobre a possibilidade de debater na escola questões que são reproduzidas pela herança eurocêntrica dos conteúdos curriculares. E nela, pensarmos aprofundar no conhecimento sobre as questões de identidade étnico-raciais presente no acervo cultural da sociedade brasileira. Acreditamos que possa contribuir na formação ampla de respeito ao sujeito.

A corrente Cultura Corporal possui uma ampla aceitação entre os pesquisadores da área da Educação Física Escolar como meio de analisar dados da realidade dos sujeitos que compõem o cenário social, entretanto, acreditamos que seja necessário conhecermos sobre a cultura produzida historicamente pela teoria moderna do racialismo que através das atitudes racistas promoveram conseqüências para a sociedade. Nesse sentido, é mister conhecermos a sua totalidade para compormos um cenário identitário de investigação e superação ao trato das questões de raça e etnia somente pelo viés universal.
Classifico como oportuno o diálogo neste texto para pensarmos no âmbito da Educação Física questões de identidade principalmente nos aspectos étnico-raciais como fenômeno a ser investigado, considerando o uso metodológico dialético e fenomenológico para formular referencial que privilegie um modelo de educação que atenda aos direitos humanos em aspectos do respeito, reconhecimento e trabalho com o outro e para o outro. Para irmos além, pensar na promoção do modelo de sociedade mais justa e igualitária.

\section{Referências}

DAOLIO, Jocimar. Educação Física e o conceito de Cultura. Campinas: Autores Associados, 2004. MINAYO, Maria Cecília. O desafio do conhecimento: pesquisa qualitativa em saúde. 8. ed. São Paulo: Hucitec, 2004, p. 50-70. MENESES, Maria Paula G. Outras vozes existem, outras histórias possíveis. In: II Congresso Internacional Cotidiano Diálogos sobre Diálogos. Niterói: UFF, Março de 2008.

SILVA, Tomaz Tadeu da. Documentos de identidade: uma introdução às teorias do currículo $2^{a}$ edição. Belo Horizonte: Autêntica, 2005. 
TODOROV, Tzveten. Nós e os Outros: a reflexão francesa sobre a diversidade humana, tradução de Sérgio Góes de Paula. Rio de Janeiro: Jorge Zahar, 1993, p.20-150.
Portal G1. http://www.g1.globo.com último acesso em 02/08/2008

Recebido: 30/agosto/2009

Aprovado: 25/outubro/2009 